\title{
TRANSFORMATIVISMO EN LAS ESTRUCTURAS TEMÁTICAS Y NARRATIVAS EN EL QUIJOTE
}

\author{
José Luis Alonso Hernández \\ Rijksuniversiteit
}

Groningen

Toda transformación comporta, como mínimo, dos polos o elementos extremos: uno el ocupado por el ser de lo representado, el otro ocupado por la representación de lo representado después del proceso de transformación. Entre estos dos polos extremos pueden existir una serie de elementos intermediarios que corresponden a las diversas fases de la transformación hasta su versión definitiva ofijada en un momento cualquiera de la que parte todo proceso de análisis; análisis que puede operarse en dos direcciones contrarias. Bien en una dirección retro-activa que tendrá como misión el descubrir y poner de manifiesto cada una de las fases, variables en cuanto al número, de la transformación y, en última instancia, la identidad del ser representado; bien en una dirección progresiva, hacia adelante, cuya finalidad es la elaboración de nuevas representaciones siempre a través de un proceso transformativo.

En lingüística, si seguimos la terminologia de Chomsky, los dos polos extremos corresponden respectivamente a la llamada estructura profunda y estructura superficial. Si tomamos la terminología del lingüista soviético Saumjan corresponden a los llamados nivel del genotipo y nivel del fenotipo respectivamente. En lo que concierne a este trabajo, y puesto que se trata de una aplicación de la lingüística transformativa al análisis del relato, creo que conviene hacer una nueva distinción terminológica, que espero quede justificada a lo largo del estudio, según la cual, estructuras profundas y genotipos corresponden a lo que llamaremos referente, mientras que estructuras superficiales y fenotipos corresponden a lo que llamaremos representación.

Estas observaciones preliminares en lo que respecta a la descripción mínima de los componentes que supone toda transformación pueden parecer obvias. Veremos que, aplicadas al relato, y sobre todo a un tipo de relato particular como es El Quijote, no lo son, y que, por el contrario, plantean 
problemas que complican bastante la descripción nuclear y mínima que acabamos de hacer.

Las transformaciones que podemos descubrir en El Quijote son de dos tipos fundamentalmente:

a) Por una parte, transformaciones de los aconteceres en el interior del relato.

b) Por otra parte, transformaciones temáticas y narrativas a partir de antecedentes folklóricos de procedencia mítica o carnavalesca en la línea de lo expuesto por Propp en su Morfologia del cuento. Es decir, transformación de estructuras exteriores al relato y que aparecen en él cambiadas, transformadas, $y$, a veces muy alejadas de las formas estereotipadas primitivas que las originan.

Si intentamos situar el lugar que el referente y la representación ocupan en los dos tipos de transformaciones que acabo de señalar nos encontramos con, en lo que respecta al apartado a), transformaciones de los aconteceres interiores al relato:

1. Una representación que procede de una transformación previa (por ejemplo rústica labradora).

2. Un referente de lo transformado (en nuestro ejemplo, Dulcinea). Así pues,

$$
\frac{\text { referente }}{\text { Dutcinea }} \quad \frac{\text { transformación }}{>} \quad \frac{\text { representación }}{\text { rústica labradora }}
$$

Tanto el referente como su representación están presentes en el relato; son explícitos.

En cuanto al apartado b), transformaciones temáticas y narrativas a partir de antecedentes folklóricos etc., nos encontramos con:

1. Un referente exterior al relato (cuento popular o mito). Se trata, pues, de un referente implícito. (Por ejemplo, el esquema clásico - carencia o daño/petición de ayuda-ayuda/reparación de la carencia o daño iniciales- en el que se basan todos los cuentos analizados por Propp.)

2. Una representación más o menos próxima o alejada del referente que le sirve de base. Representación que se encuentra en el relato 
bajo una forma transformada. (Por ejemplo, la historia de la dueña doña Rodríguez y de su burlada hija que origina la descomunal y nunca llevada a cabo batalla del lacayo Tosilos y de don Quijote, y que termina con la victoria de éste por abandono del campo del contrario y promesa de matrimonio que, si no tiene lugar por designio vengativo y posterior del duque, es cuestión zanjada para don Quijote desde el momento en que todos declaran estar de acuerdo con las premisas y consecuencias del malogrado combate.)

Podrá argüirse inmediatamente que la clasificación que acabo de hacer es posible merced al hecho de situarme en dos niveles diferentes. Por una parte, a nivel de los personajes del libro y sus acciones, por otra a nivel de la visión que el lector tiene del libro como objeto exterior a él y analizable como tal. Si la argumentación resulta válida para la mayor parte de los episodios del libro, veremos también que, para otros, existen "rambigüedades de visión» que hacen que ni los personajes ni el lector se determinen o puedan decidirse acerca de si un determinado acontecimiento es «real» (siempre dentro de la ficción del relato) o transformado. Así, personaje observador, agente o testigo, y lector, se encuentran a veces en una situación idéntica de ambigüedad con respecto a la valoración que hay que atribuir a un determinado episodio sin poder determinar si se trata de un referente o de su representación. Algunos de los ejemplos que daré más adelante aclararán, espero, lo que aquí anuncio de manera somera.

Dentro de las transformaciones de los aconteceres en el interior del relato (apartado a)) podemos hacer la siguiente subdivisión:

a) Transformación de las acciones de los personajes. Los ejemplos que he elegido para analizar este caso de transformación se basan en la dualidad burlas veras que ocupan una parte importante de los acontecimientos que tienen lugar durante la estancia de don Quijote y Sancho en casa de los Duques.

b) Transformación del mundo «real» (insisto, siempre dentro de la ficción que es la novela) y de los personajes que actúan en él. Esta transformación ocurre a su vez a niveles diferentes que analizaré en el doble aspecto de sujeto o agente de la transformación y en el de objeto o paciente de la transformación. Estos niveles de transformación ocurren principalmente por:

1. Obra de don Quijote que atribuye a la «realidad» una significación diferente de la que en sí se tiene con objeto de poder actuar sobre ella de acuerdo con sus designios y profesión de caballero andante. Por ejemplo:

venta y ventero $>$ castillo y castellano (I, II y III). 
molinos $>$ gigantes (I, VIII).

rebaños $>$ ejércitos (I, XVIII)!

2. Encantamiento burlesco, por ejemplo:

Dulcinea $>$ rústica labradora (obra de Sancho) (II, X). Caballero de los Espejos > Sansón Carrasco (obra de don Quijote, a posteriori, para justificar su victoria) (II, XII a XVI).

dueña (mayordomo) $>$ Dolorida o Trifaldi (obra de los Duques) (II, XXXVI a XLI).

labrador > Tosilos (obra de los Duques) (II, LVI)!

3. Transformación por ósmosis. La más importante es la de don Quijote en Sancho y viceversa, con las limitaciones que impone el caso:

don Quijote Sancho

En lo que se refiere a las transformaciones temáticas y narrativas a partir de antecedentes folklóricos etc., (apartado b)), haremos asimismo, una subdivisión entre:

a) Transformación de unidades temáticas. Los ejemplos que he elegido son algunos de los viajes más representativos de los héroes a partir de la distinción que hace Propp entre las formas especificas de viajar en verticalidad (profundidad y altura) o en horizontalidad.

Así pues:

el descenso a la Cueva de Montesinos (II, XXIII)

el viaje en el Barco Encantado (II, XXIX)

el viaje sobre Clavileño (II, XLI)

no podían estar ausentes de este apartado.

b) Transformación de las estructuras narrativas que se realizan en las siguientes direcciones:

1. Distorsión de estructuras narrativas, tradicionales cuya función es la de diversificar, en apariencia, contenidos idénticos del punto de vista temático.

2. Inclusión en las estructuras narrativas de contradicciones lógicas, léxicas y semánticas, en la perspectiva de yuxtaposición de elementos "normales" como creadores de contexto, y elementos «a-normales» con respecto a dicho contexto y viceversa.

Esta clasificación de las transformaciones ocurrentes en El Quijote no pretende ser, ni mucho menos, exhaustiva. Se trata únicamente de un esbo- 
zo mínimo que sin duda podría ser ampliado. Además, conviene tener en cuenta que intenta ser una clasificación dinámica, es decir, en la que los diversos apartados señalados se encuentran con puntos de interferencia cuando son aplicados a un mismo episodio.

Resumiendo lo que acabamos de decir nos encontraríamos con el siguiente esquema:

a) Transf. aconteceres

b) Transf. te. máticas-narrat. repres. inter.

repres. inter. relato

refe. inter. relato

refer. exter. relat. (1) a) transf. acciones

b) transf. «realidad»

1. por d. Quijote

2. burlesca

3. ósmosis

a) transf. temáticas

b) transf. narrativas
1. distorsión

2. inclusión

Pasemos ahora al análisis de cada uno de los apartados apuntados.

En lo que se refiere a la transformación de los aconteceres, apartado a) transformación de las acciones de los personajes, deciamos un poco antes que los ejemplos que he elegido son aquellos que se basan en la dualidad burlas veras y que la mayoría de ellos se encuentran en los episodios que tienen lugar durante la relación entre los Duques y don Quijote y Sancho. En todos los casos se trata de la transformación de un episodio inicialmente planteado como una burla y que en el transcurso se convierte en veras o viceversa, de unas veras, con frecuencia ridículas pero no por ello menos veras, que terminan en burlas.

Este tipo de transformación lo encontramos explícitamente formulado, por lo menos, en tres ocasiones que tienen todos los visos de ser la opinión e intención de Cervantes, aunque en un caso se presente a través del narrador (que no hay que confundir con el autor) y en los otros dos, a través de los personajes del relato.

La base de la transformación puede resumirse así:

(esquema I): discreto, discreción (verdad) > loco, locura (burla) o en el sentido inverso: dad)

(esquema II): loco (necio), locura (burla) > discreto, discreción (ver-

El ejemplo de la transformación presentado a través del narrador res- 
ponde al esquema I donde el a priori discreto, se convierte, mediante su actuación en necio o de burlador en burlado. Así en el capítulo LXX de la segunda parte se escribe:

"Y dice más Cide Hamete: que tiene para sí ser tan locos los burladores como los burlados, y que no estaban los duques dos dedos de parecer tontos, pues tanto ahínco ponian en burlarse de dos tontos."

Los otros dos ejemplos de transformación presentados a través de los personajes van en el mismo sentido y con frases casi idénticas.

El primero describe la actuación de Sancho como gobernador de la Insula Barataria y responde al esquema II. El a priori necio, tonto o burlado de Sancho se convierte, mediante su manera de actuar, en discreto y burlador. El mayordomo que le acompaña por orden de los duques con la misión de montar toda clase de burlas no tiene más remedio que declarar, reconociendo la inversión de los papeles en la acción.

"Cada día se veen cosas nuevas en el mundo: las burlas se vuelven en veras y los burladores se hallan burlados». (II, XLIX).

El segundo ejemplo, también presentado a través de uno de los personajes del libro, responde al esquema I, es decir, exactamente igual que en el caso presentado a través del fingido narrador Cide Hamete. Cuando don Quijote se pasea por Barcelona en compañia de los caballeros catalanes y con un rótulo en la espalda que proclama su identidad (II, LXII), un castellano que ve el cortejo dice:

«Tú [don Quijote] eres loco, y si lo fueras a solas y dentro de las puertas de tu locura, fuera menos mal; pero tienes propiedad de volver locos y mentecatos a cuantos te tratan y comunican; si no mirenlo por estos señores que te acompañan».

El resto de la cita es prácticamente idéntica a la reprensión que el malhumorado eclesiástico de los duques le hace a don Quijote durante la comida (II, XXXI).

A pesar de la aparente diferencia que existe entre los tres ejemplos basada en la diferencia del relator, Narrador/Personajes, insisto en que, en realidad, se trata de observaciones de carácter general cuya función es narrativa y sirve para señalar la identidad de mensaje en el que lo que son burlas devienen veras y lo que son veras devienen burlas.

Estas observaciones de carácter general encuentran su explicación directa, se ejemplifican, en los episodios en los que don Quijote y Sancho intervienen. 
Estos episodios se presentan de tres maneras diferentes:

1. Episodios-burla en los que:

a) unos personajes están al tanto de la burla y la mayoría de las veces son los instigadores de ella.

b) otros personajes se comportan como observadores de los acontecimientos y no saben qué significado atribuirles en la medida en que desconocen que se trata de una burla.

Como ejemplo tenemos el de la batalla entre don Quijote y Tosilos (II, LVI) a propósito de la deshonra de la hija de doña Rodríguez. Batalla en la que unos juegan el papel de amañadores preparando una justa con tal apariencia de veracidad que atrae de las,

"aldeas circunvecinas infinita gente, a ver la novedad de aquella batalla; que nunca otra tal no habian visto ni oido decir, en aquella tierra los que vivian ni los que habian muerto".

mientras que los otros, los venidos como observadores de las aldeas circunvecinas,

"quedaron tristes y melancólicos, de ver que no se habian hecho pedazos los tan esperados combatientes...".

Hacerse pedazos que estaba muy lejos de las verdaderas intenciones del Duque pero que los observadores no podían interpretar más que bajo la apariencia de realidad que el fingimiento prometía.

Este tipo de episodio-burla es llevado a veces al extremo de que aún los mismos burladores se sienten tan imbuidos de la veracidad de la acción que adoptan un comportamiento semejante al de un observador ajeno a la traza. Asi, la Trifaldi cuenta sus cuitas,

«con tanto sentimiento... que sacó las lágrimas de los ojos de todos los circunstantes, y aún arrasó los de Sancho..." (II, XL).

Sancho y don Quijote son en este caso los destinatarios de la burla; los circunstantes, todos, son los amañadores de la misma; lo que no impide que unos y otros lloren como si se tratara de un verdadero y lamentable caso de encantamiento.

2. Episodios-burla en los que el burlador (agente de la burla) se ve obligado a participar en ella como paciente de la misma, incluso, a ve- 
ces, en contra de su propia voluntad. Es un caso extremo de burlador que se convierte en burlado.

El ejemplo más notable es el del final del citado desafio de Tosilos y don Quijote, donde Tosilos se declara vencido y dispuesto a casarse con la hija de doña Rodríguez lo que impide que el combate se lleve a cabo por lo que el Duque,

«quedó suspenso y colérico en extremo...".

A pesar de la cólera del Duque en la que se insiste varias veces, el personaje se ve obligado a llevar adelante la burla pero por unos caminos que él no había sospechado y en los que de agente o fabricante de burla se encuentra transformado en paciente de la misma. La consciencia del Duque acerca del papel que se ve obligado a representar justifica, como se dirá más tarde (II, LXVI), la resolución que toma de hacer dar cien palos a Tosilos, meter monja a la hija de doña Rodríguez, y enviar a ésta a Castilla. Es su venganza por haber sido objeto de una burla que él mismo habia montado para otros.

3. Intervención de las veras en un contexto de burlas. Se trata de episodios burlescos en cuyo desarrollo aparecen o se incrustan otros que deben su existencia al planteamiento burlesco pero cuyo desarrollo posterior nada tiene que ver con una burla. Nos encontramos así, con un episodio concebido como burla desde el principio hasta el final en cuyo interior se generan otros imprevistos e involuntarios para los burladores que se encuentran arrastrados por la "veracidad" de la nueva situación.

Un ejemplo de este tipo es cuando la ronda nocturna de Sancho y sus acompañantes, que es una burla más de las ordenadas por los duques y sus criados, se encuentran con los dos jóvenes hermanos disfrazados que desean ver mundo (II, XLIX). El resultado de este encuentro no previsto en la burla, es que el maestresala-burlador se enamora de la doncella y concibe el propósito de pedirla por esposa a su padre, confiando en el apoyo de su amo el Duque. Notemos que el mismo episodio anima a Sancho con repecto al mancebo hermano de la doncella a quien piensa casar con su hija Sanchica utilizando para ello sus prerrogativas de gobernador. La diferencia estriba en que mientras el proyecto de Sancho se asienta en una situación falsa, de burla (no es un verdadero gobernador) incontrolada por él y es irrealizable, el proyecto del maestresala se asienta sobre la realidad (puede tener el apoyo del Duque, su amo) y tiene posibilidades de realizarse. Este paralelismo en cuanto a las intenciones de los personajes burladores o burlados, in- 
dependientemente de su realización (después de todo no se dice si el maestresala lleva a cabo sus deseos o no) tiene como función mostrar que el límite que separa la ficción de la realidad es estrecho y con frecuencia difuso.

Del mismo estilo, también durante la ronda de Sancho, son los encuentros con el tahur y el mirón por una parte y con el gracioso tejedor de hierros de lanzas por otra (II, XLIX), sobre cuyas historias no podemos decidirnos a situarlas en el campo de la ficción burlesca o de la realidad, ya que pueden ser tan to lo uno como lo otro. Sólo un poco más tarde, con el hallazgo de los citados hermanos, una frase parece indicarnos que ambas aventuras han sido producto de una burla:

"y los consabidores de las burlas que habian de hacer a Sancho fueron los que
más se admiraron, porque aquel suceso y hallazgo no venía ordenado por
ellos, y asi, estaban dudosos, esperando en qué pararia el caso".

Si este suceso «no venía ordenado por ellos» es quizás una indicación de que los anteriores si lo venían.

Un caso que podría parecer, dentro del mismo esquema, diferente de los anteriores, es el de la petición de ayuda a don Quijote por parte de la dueña doña Rodriguez. En efecto, sin ningún ánimo de burla la dueña pide amparo para su deshonrada hija (II, XLVIII). El resultado de esta iniciativa será por una parte el vapuleo que ambos sufren (lo que es una burla) y el reto que don Quijote lanza al ausente agraviador aceptado por el Duque (II, III) y que trae como consecuencia la justa con el lacayo Tosilos (planteada también como burla). Así presentado, se trataría de una situación invertida.en la que un contexto de veras genera una situación burlesca. Nada más falso. Si doña Rodriguez pide seriamente ayuda a don Quijote es porque el contexto anterior (que es burlesco para todo el mundo menos para la dueña) presenta a don Quijote como un verdadero caballero andante desfacedor de entuertos, y doña Rodríguez lo juzga así. Se trata, pues, de una estructura ligeramente más complicada que podría resumirse así:

\begin{tabular}{|c|c|c|}
\hline $\begin{array}{l}\text { Don Quijote cree ser } \\
\text { un verdadero caba- } \\
\text { llero andante y todos } \\
\text { contribuyen a esta } \\
\text { creencia. }\end{array}$ & $\begin{array}{l}\text { Doña Rodríguez cree } \\
\text { que Don Quijote es } \\
\text { un defacedor de en- } \\
\text { tuertos y le pide } \\
\text { ayuda. }\end{array}$ & $\begin{array}{l}\text { Los demás prolon- } \\
\text { gan la burla inicial } \\
\text { utilizando la verídica } \\
\text { ignorancia de doña } \\
\text { Rodriguez. }\end{array}$ \\
\hline
\end{tabular}

En resumen, se trata del mismo esquema estructurado sólo que repetido en su fase burlesca, lo que no es más que una de las argucias frecuentes en el cuento folklórico.

A mi parecer que la inclusión de acontecimientos «verídicos» en con- 
textos burlescos tiene una función semejante a la de la inclusión de novelas ajenas en gran parte al relato (Cervantes mismo lo dice II, XLIV) de la primera parte cuya misión es actuar de contraste. Sólo que aquí, la inclusión se hace de manera mucho más sutil y en consecuencia su interpretación resulta difícil. No son episodios añadidos. Son episodios generados por el relato mismo con el que se confunden a menudo.

En lo que se refiere al segundo apartado (apartado $b$ )), transformación del mundo «real» y de los personajes que actúan en él, decíamos que podían ser de tres tipos que, como veremos, están estrechamente emparentados.

El primero, transformación del mundo "real» por don Quijote, se presenta como una necesidad en la medida en que las pretensiones del héroe: ser caballero andante, enderezar entuertos, amparar desvalidos, etc., no pueden llevarse a cabo en el marco de la realidad de su tiempo. Se hace necesario pues, quijotizar el mundo, es decir, hacerlo apto para poder actuar sobre él según sus designios. Notemos que son muy pocos los casos en que la realidad se presta a una actuación digna del reparador de injusticias que es don Quijote, y que en estos casos su intervención resulta un fracaso. Así en la aventura del azotado Andrés (I, IV) que don Quijote cree dejar resuelta favorablemente para la víctima pero que, en realidad, con el tiempo, vendremos a descubrir que precisamente a causa de la intervención de don Quijote no hace más que convertirse en doblemente injusta, puesto que su amo no sólo no le paga lo que le debe sino que le dobla la tanda de azotes. La reacción de Andrés no puede ser más significativa con respecto a la intervención de los caballeros andantes en asuntos ajenos:

«Por amor de Dios, señor caballero andante, que si otra vez me encontrare, aunque vea que me hacen pedazos, no me socorra ni ayude, sino déjeme con mi desgracia; que no será tanta, que no sea mayor la que me vendrá de su ayuda de vuestra merced, a quien Dios maldiga, y a todos cuantos caballeros andantes han nacido en el mundo». (I, XXXI).

El mismo fracaso encontramos en la ya citada aventura de doña Rodríguez y su deshonrada hija, que lejos de recuperar la perdida honra es metida en un convento...

Así pues, y como regla general, puede decirse que en los casos en que en la realidad aparece un daño que exige reparación, la intervención del héroe no hace más que agravar el daño inicial. Se trata, pues, de una inversión con respecto a la estructura básica del cuento pupular tal y como la describe Propp en su Morfologia del cuento, donde toda carencia o daño se encuentra reparada el final.

En el resto de las aventuras del Quijote, que son la mayoría, o bien don Quijote empieza por transformar la realidad para crear una situación propicia en la que poder intervenir con resultados variables, o bien la realidad viene ya transformada por medio de una burla y don Quijote no tiene más que adaptarse a la situación propicia que los otros crean para él.

Ejemplo del primer tipo de transformación es la conversión de la venta y 
el ventero de los capítulos II y III de la primera parte en castillo y castellano, absolutamente necesaria para don Quijote que parte del principio de que para actuar como un caballero andante tiene que ser armado caballero según la tradición de los libros de caballería. Como en los mismos libros los caballeros se encuentran con frecuencia con gigantes a los que combaten, don Quijote transforma los molinos de viento en gigantes para tener derecho a este tipo de aventura. Notemos que en este caso el gigantismo de don Quijote se basa sobre todo en el tamaño propiciado por el de los molinos mientras que en los libros de caballería el jayán, que es duplicado de gigante, es un «hombre común, pero de estatura y fuerzas notables» (Dicc. Etimológico de Corominas y yo añadiría que casi siempre perverso. Es decir, en el Quijote, se trata de gigantes desmesurados. Por último, y por no citar más, otro ejemplo de este tipo de transformación es el de los rebaños de ovejas en ejércitos que se combaten (I, XVIII).

En todos los casos de este tipo de transformaciones nos encontramos con un esquema de base que es:

\section{$\underline{\text { realidad }>\text { transformación-actuación }>\text { realidad }}$}

La última fase de vuelta a la realidad puede faltar, según los casos, en lo que se refiere al reconocimiento de dicha realidad por parte de don Quijote.

Los tiempos del relato o presentación temporal de cada uno de los elementos del esquema de base son variables aunque el más frecuente es la presentación de la realidad inicialmente por parte del narrador. A este propósito conviene hacer una distinción entre el discurso del narrador y el discurso de los personajes. Mientras el primero nos sitúa casi siempre en la fase de realidad con una función aclaratoria el personaje nos sitúa en la fase de transformación. A partir del esquema de base señalado y teniendo en cuenta el tiempo del relato y el sujeto del discurso aplicado a los tres ejemplos citados, nos encontramos con lo siguiente:

Aventura de la venta-castillo (I, II y III):

\begin{tabular}{|l|c|c|c|}
\hline & realidad & transformación-acción & realidad \\
\hline Narrador & I (venta) & & III (venta) \\
\hline don Quijote & & II (castillo) & \\
\hline
\end{tabular}

Aventura de los molinos-gigantes (I, VIII): 


\begin{tabular}{|l|c|c|c|}
\hline & realidad & transformación-acción & realidad \\
\hline Narrador & I (molinos) & & III (molinos) \\
\hline don Quijote & & II (gigantes) & III (encantam.) \\
\hline Sancho & I (molinos) & & III (molinos) \\
\hline
\end{tabular}

Aventura de los rebaños-ejércitos (I, XVIII):

\begin{tabular}{|l|c|c|c|}
\hline & realidad & transformación-acción & realidad \\
\hline Narrador & II (ovejas) & & III (ovejas) \\
\hline don Quijote & & I (ejércitos) & III (encantam.) \\
\hline Sancho & II (ovejas) & I (ejércitos) & III (ovejas) \\
\hline
\end{tabular}

(NOTA) Los números romanos indican los tiempos del relato.

En el ejemplo de la venta don Quijote no acepta ni se plantea que sea otra cosa que castillo. En el caso de los molinos-gigantes y de las ovejas-ejércitos acepta que se trata de molinos y de ovejas en la fase final pero merced a un encantamiento de sus enemigos para quitarle la gloria de su vencimiento. Es decir, a partir de su propia realidad que es la transformación, don Quijote admite una transformación en la que la realidad final es lo que en verdad ha sufrido una transformación.

Las transformaciones obra de encantamientos burlescos (apartado $b$ ) punto 2) se caracterizan por el hecho de venir ordenadas no por don Quijote, sino por el resto de los personajes del libro. Los llamo encantamientos burlescos porque en todos los casos se trata de transformaciones de la realidad hechas por personajes conscientes de cuál es la realidad y cuál la transformación. Además, la mayoría de las veces el objetivo es burlarse de don Quijote y asi ocurre en todos los episodios que tienen lugar en casa de los Duques. En otros casos el objetivo es salir de una situación apurada, como cuando Sancho transforma a Dulcinea en labradora al darse cuenta muy bien de que Dulcinea no existe más que en la imaginación de su amo y no saber, pues, como cumplir con la embajada que éste le ha ordenado. Incluso puede tratarse de una burla preparada con la caritativa intención de volver a don Quijote a su sano juicio y de este estilo son las burlas y encantamientos que preparan sus vecinos y amigos, el cura, el barbero, Sansón Carrasco, y que son precisamente las que terminan con la vida del héroe.

Como es lógico, la estructura de este tipo de transformaciones es más complicada que la de las anteriores. La razón es simple. Mientras que en las transformaciones obra de don Quijote éste es agente y paciente al mismo 
tiempo, de manera que cambia o interpreta la realidad a la justa medida de sus deseos y en la medida en que la transformación le sirva exclusivamente para el tipo de acción que pretende realizar, en las transformaciones burlescas, que vienen de los otros personajes y van destinadas a don Quijote, la coincidencia entre transformación y acción no puede ser tan perfecta. De ahi que necesiten mayor aparato, todo un montaje teatral destinado a evitar que don Quijote interprete la burla como burla y se abstenga, en consecuencia, de actuar.

Empleando el mismo esquema que el utilizado en las transformaciones anteriores y aplicado aqui al encantamiento de Dulcinea y a la aventura del Caballero de los Espejos, tenemos:

Aventura del Encantamiento de Dulcinea (II, X):

\begin{tabular}{|c|c|c|c|}
\hline & realidad & transformación-acción & realidad \\
\hline \multirow[b]{2}{*}{ Narrador } & Dulcine $a=\emptyset$ & \multirow[t]{2}{*}{ V (labradora por encanto) } & \multirow{2}{*}{$\begin{array}{l}\text { Dulcine } a=0 \\
\text { VIII }\end{array}$} \\
\hline & $\begin{array}{l}\text { III (tres labra- } \\
\text { doras) }\end{array}$ & & \\
\hline \multirow{2}{*}{ don Quijote } & I Dulcinea & \multirow[t]{2}{*}{ VI (labradora por encanto) } & \multirow{2}{*}{$\begin{array}{l}\text { IX (Dulcinea }=0 \text { ) } \\
\text { (testamento) }\end{array}$} \\
\hline & IV (labradora) & & \\
\hline Sancho & Dulcine $a=\varnothing$ & $\begin{array}{l}\text { Il (labradora-burla) } \\
\text { VIII (labradora en casa de } \\
\text { los Duques) }\end{array}$ & \\
\hline
\end{tabular}

Notemos que en este caso la actitud inicial de Sancho es idéntica a la del narrador: Dulcinea no existe. Después, cogido en su misma trampa, en casa de los Duques no sólo admite que lo que él creía ser un encantamiento trazado en su imaginación puede ser la verdadera realidad, sino que incluso el desencantamiento tiene que hacerse a través del propio encantador que es él mismo.

Para don Quijote, Dulcinea dejará de existir al recuperar el juicio y hacer el testamento, como deja de existir todo lo demás y la misma razón de su vida.

Aventura del Caballero del Bosque o de los Espejos (II, XII):

\begin{tabular}{|l|l|l|l|l|}
\hline \multirow{2}{*}{} & \multirow{2}{*}{ realidad } & \multicolumn{2}{|c|}{ transformación-acción } & \multirow{2}{*}{ realidad } \\
\cline { 3 - 4 } & & \multicolumn{1}{|c|}{ I. $^{a}$ fase } & \multicolumn{1}{|c|}{${ }^{a}$ fase } & \\
\hline Narrador & $\begin{array}{l}\text { I (Cab. Espe- } \\
\text { jos) }\end{array}$ & II (S. Carrasco) & III (S. Carrasco) \\
\hline don Quijote & $\begin{array}{l}\text { I (Cab. Espe- } \\
\text { jos) }\end{array}$ & II (S. Carrasco) & \\
\hline Sancho & & $\begin{array}{l}\text { I (Cab. Espe- } \\
\text { jos) }\end{array}$ & II (S. Carrasco) & \\
\hline
\end{tabular}


En este episodio el primer contacto que el lector tiene con el sujeto de la acción es cuando éste aparece ya transformado en Caballero de los Espejos sin que, sin embargo, la transformación aparezca evidente hasta el final de la aventura donde se descubre que se trata de Sansón Carrasco. Hasta entonces, no se sabe si se trata de un personaje transformado o de un personaje "real»; otro loco como don Quijote. Para don Quijote y para Sancho la transformación interviene cuando el Caballero de los Espejos es vencido. De ahi que se haga necesario distinguir entre dos fases de transformación o dos transformaciones diferentes.

Comparando los dos tipos de transformación que acabamos de analizar (obra de don Quijote/obra del resto de los personajes) nos damos cuenta que a medida que el relato avanza las transformaciones, obra de don Quijote, se hacen cada vez más raras y espaciadas y, en cambio, las transformaciones del resto de los personajes son cada vez más frecuentes. Hasta el punto de que podemos generalizar diciendo que las transformaciones obra de don Quijote son características de la primera parte del libro mientras que las otras lo son de la segunda. Efectivamente, en la segunda parte del Quijote son los otros personajes los que transforman la realidad. Don Quijote se limita a comportarse dentro de una realidad ya transformada y podríamos decir que a medida que el mundo exterior se quijotiza, deviene apto para las aventuras de don Quijote sin que éste tenga que intervenir en ello, don Quijote se des-quijotiza, pierde progresivamente fuerza hasta el final definitivo en que deja de ser don Quijote para devenir Alonso Quijano:

«Dadme albricias, buenos señores, de que ya no soy don Quijote de la Mancha, sino Alonso Quijano, a quien mis costumbres me dieron renombre de Buenom. (II, LXXIV).

Si en este caso la cita es explícita, en realidad ya venía anunciada desde mucho antes. Señalemos que en esta parte del libro Sancho se independiza cada vez más de su amo e incluso llega a suplantarlo como sujeto de aventuras. A la vez los casos en que don Quijote no transforma nada son frecuentes y explícitos. En el capítulo LIX de la segunda parte la venta es venta y no castillo y dice el narrador:

"volvieron a subir y a seguir su camino, dándose prisa para hegar a una venta que, al parecer, una legua de allí se descubria. Digo que era venta porque don Quijote la llamó así, fuera del uso que tenia de llamar a todas las ventas castillos".

Y lo mismo en el capítulo LXXI:

«Apeáronse en un mesón, que por tal le reconoció don Quijote, y no por castillo de cava honda, torres, rastrillos y puente levadiza; que después que le vencieron, con más juicio en todas las cosas discurría...". 
En realidad, el discurrir con más juicio viene de antes del vencimiento y es paralelo a la independización de Sancho que ocupa progresivamente el lugar de su amo, operándose lo que llamaba al principio una transformación por ósmosis (apartado b) 3) mediante la cual Sancho se quijotiza, transforma el mundo, se cree gobernador, y don Quijote declina hasta recuperar el juicio.

Cuando Sancho, al final del libro, se da cuenta de la transformación sufrida por don Quijote, hará todos los esfuerzos posibles para evitar su muerte y él es quien insiste en la conversión a la vida pastoril en el plazo del año en que tienen que encerrarse en el pueblo, esperando el término para continuar con nuevas aventuras. Creo que esta transformación por ósmosis merecería un desarrollo aparte y por sí sólo, pero quédese de momento aquí.

Los ejemplos que podríamos aducir para ilustrar las transformaciones de las estructuras ocurrentes en El Quijote son imnumerables debido sobre todo al hecho de que la deuda del libro hacia las narraciones de carácter folklórico y popular no necesita demostración. Por mi parte me he limitado al tema del viaje que es una de las características constantes del cuento popular como lo describe Propp. Efectivamente la actuación del héroe va siempre ligada a un desplazamiento espacial que es el que, en último término, le depara las aventuras y encuentros sobre los que actúa. Las aventuras del héroe ocurren precisamente porque abandona el lugar de su residencia habitual. Propp señala que los desplazamientos se hacen en horizontalidad o en verticalidad (sea en profundidad o en altura). Los tres tipos de desplazamientos tienen lugar en el Quijote, y para ilustrarlos he elegido la aventura del Barco Encantado (ejemplo de horizontalidad), la Cueva de Montesinos (verticalidad en profundidad) y la aventura de Clavileño (verticalidad en altura). Notemos enseguida que se trata de desplazamientos extraordinarios o presentados como tales. En lo que se refiere al desplazamiento ordinario, el hecho de andar o ir en un caballo normal, no mágico, lo frecuente en el Quijote es que éste no lleve un rumbo fijo y deje vagar a Rocinante a su guisa o pida a Sancho que guie por donde mejor le pareciere. Sólo en el caso del rumbo fijo a Barcelona, justificado para desmentir al autor del falso Quijote, y en pocos casos más, el destino está explicitado.

Al comparar los viajes del cuento popular con los arriba citados del Quijote, lo primero que nos llama la atención es que si el viaje del cuento popular tiene lugar, se trata de un desplazamiento real aunque con frecuencia marcado con el sello de la exageración y la imposibilidad, en el caso de los viajes del Quijote el desplazamiento no tiene lugar o dentro de unos límites que están muy alejados de los que exigiría la aventura que generan. Así pues, nos encontramos con una prácticamente inmovilidad por una parte, $y$ por otra con una aventura para cuya realización el desplazamiento es absolutamente necesario. La solución de la contradicción reside en el hecho de convertirlos en viajes imaginarios.

En la aventura de la Cueva de Montesinos se trata de una transforma- 
ción onírica. El sueño fisico, la siesta de don Quijote crea la realidad y la preña de una posibilidad de aventura.

En la aventura del Barco Encantado se trata del sueño de la razón. Don Quijote transforma en su imaginación la realidad para poder actuar sobre ella en las perspectivas que antes hemos señalado.

En la aventura de Clavileño la realidad viene transformada del exterior. Don Quijote ni sueña ni imagina para transformar la banalidad de la realidad.

En las dos primeras aventuras-viaje el narrador del viaje es don Quijote. Sancho no cree nada; duda, critica y niega.

En la tercera aventura-viaje el narrador de lo maravilloso es Sancho. Don Quijote duda y niega y por último utiliza el chantaje para hacer admitir a su escudero la veracidad de la aventura de Montesinos:

"y llegándose don Quijote a Sancho, al oido le dijo:

-Sancho, pues vos queréis que se os crea lo que habéis visto en el cielo, yo quiero que vos me creáis a mi lo que vi en la cueva de Montesinos. Y no os digo más". (II, XLI).

Así pues, los papeles se encuentran invertidos como señalaba a propósito de las transformaciones por ósmosis.

Señalemos también, que las aventuras más elaboradas, ricas en detalles, son la de la cueva de Montesinos y la de Clavileño. Ahora bien, en el primer caso decimos que se trata de elaboración onírica mientras que en el segundo se trata de una teatralización carnavalesca. Hay pues una correspondencia estructural entre la elaboración onírica y el espectáculo carnavalesco. Montesinos, Durandarte, Belerma y los demás, encuentran su correspondiente en Clavileño, Dolorida, Trifaldín, etc. Podríamos llegar a la conclusión de que el mundo carnavalesco es una imitación del mundo onírico. Ambos son liberadores para el sujeto que los sufre o practica. El sujeto se integra con facilidad en una "realidad» ficticia y resuelve y soluciona el problema que se le plantea en términos idealistas. El Héroe, sea a través del sueño o de una actividad carnavalesca, encuentra un mundo construido a la medida de sus acciones.

En el caso del Barco Encantado el héroe se ve forzado a transformar la realidad para que le sirva de marco propicio a su actuación. La solución es realista y la ficción cede el campo a la realidad. Don Quijote disimula su despecho y paga los destrozos causados. No tiene posibilidad de liberarse de los fantasmas que le persiguen y el discurso que dirige a los imaginados presos no es más que un discurso de pura forma; un último y desesperado intento de no renunciar a un mundo que se le vuelve escurridizo y falso.

Con todos los tipos de transformación que hemos analizado someramente, Cervantes intenta situar al lector ante una cadena cifrada en la cual a una representación corresponde un referente interno al relato y un referen- 
te externo a él, es decir, en un sistema múltiple de desencodamiento y significación en el que se combinan:

1. Una representación.

2. Un referente interno al relato que puede estar patente o no.

3. Un referente externo al relato.

4. Un desencodamiento a nivel narrativo.

Todo ello con la finalidad de demostrar los límites de la realidad que se anuncian asimismo en la ficción del narrador Cide Hamete, verdadero autor de la historia en la que el propio Cervantes se incluye, como un personaje más en figura de cautivo. Como para demostrar que entre la vida real y la vida del relato la diferencia es nula. 